\title{
Green Synthesis of Gold Nanoparticles using Adina Cordifolia Bark Extract and its Antimicrobial and in Vitro Anticancer Study
} Shaileshkumar C Kotval

Research Scholar, Hemchandracharya North Gujarat University, Patan, Gujarat, India

\begin{abstract}
In this study, green synthesis of gold nanoparticles were success fully synthesised by using Adina cordifolia plant bark aqueous extract which provides eco-friendly process, an environmentally benign, easy and proficient way for the synthesis of gold nanoparticles. The smaller size of gold nanoparticles have research on various dieses are very important. The green synthesized gold nanoparticles were characterized by UV-Visible spectroscopy, FT-IR, XRD, SEM, TEM and their antimicrobial activity was investigated. From UV-Visible spectrophotometer result was confirmed the formation of gold nanoparticles by color changed to ruby red color from pale yellow color indicates the reduction of $\mathrm{Au}^{3+}$ ions to $\mathrm{Au}^{\circ}$. The antibacterial activity for the synthesized gold nanoparticles was confirmed by the antibacterial activity experiment against Bacillus subtilis and Escherichia coli by agar well method. The synthesized AuNPs was performed anticancer activity against MCF-7 breast cancer cell line. Compared to Adriamycin, Positive Control Compound AuNPs exhibited potent anticancer activity with the IC50. The green synthesized gold nanoparticles proved to be potential candidates for medical application antimicrobial and anticancer activity is highly essential.
\end{abstract}

Keywords: Green Synthesis, Antibacterial Activity, In Vitro Anticancer Activity

\section{INTRODUCTION}

Green synthesis of metal nanoparticles by plant extract is a simple, eco-friendly and efficient method in comparison to chemical mediated synthesis method and plant extracts acts as stabilizing agents and low-cost reducing agents ${ }^{1}$ and recently various types of metal nanoparticles are synthesized by different plant sources. Green synthesis of monodispersed nanoparticles with specific shapes and sizes has a challenge in bioscience and it has major advantages in a pharmacological industry to cure different viral and bacterial diseases ${ }^{2}$ and this ecofriendly synthesis of nanoparticles is considered as building blocks of these generations to control various diseases. The important parameters controlled for the synthesis of gold nanoparticles by concentrations of reagents, temperature, $\mathrm{pH}$, pressure, and time of reaction. Many reports related to this field states that biosynthesized nanoparticles will control oxidative stress, apoptosis-related changes, and Geno-toxicity ${ }^{3}$. First proposed by Mie by Maxwell equation AuNPs appear in red ruby color due to a surface Plasmon resonance and the reduction by reducing agents in the presence of stabilizer and the visible spectrum of wavelength of around $520 \mathrm{~nm}$ in different shapes such as rod-like, spherical, oblong etc, can be synthesized ${ }^{26}$.

Parida has done the experiment of synthesised gold nanoparticles from Allium cepa L plant extract with MCF-7 cancer cell line for in vitro anticancer studies 
and it showed AuNPs in the range of $100 \mathrm{~nm}$ in diameter and also showed that cytotoxic activity on MCF-7 cancer cell line was dose-dependent manner, Hence AuNPs effectively inhibits the growth of MCF-7 cancer cell line ${ }^{4}$. Boruah was successfully proved in vitro anti-cancer experiment in the study of cytotoxicity assay with different concentrations of AuNPs against MCF-7 cell lines from Camellia sinensis $\mathrm{L}$ plant extract and it was in the size range of $25 \mathrm{~nm}$ and results was a decrease in the percentage growth of cancer cells 5 .

Adina cordifolia (Roxb.) commonly known as Haldu is large deciduous tree species of family Rubiaceae ${ }^{6}$. The tree may attain $30 \mathrm{~m}$ height and straight clean bole of $12 \mathrm{~m}$ and a girth of $7 \mathrm{~m}$ and over, with a large high crown, erect trunk and horizontal branches (Anon, 1985). The species of flower may be insignificant individually and attractive. The bark of the tree act as an antiseptics and capable of destroying microbes, virus particles and prevent or inhibit their growth. Adina cordifolia is a traditional healer for the treatment of cough, jaundice, diarrhea, stomachache, fodder, swelling in stomach, and roots are astringent and constipating?
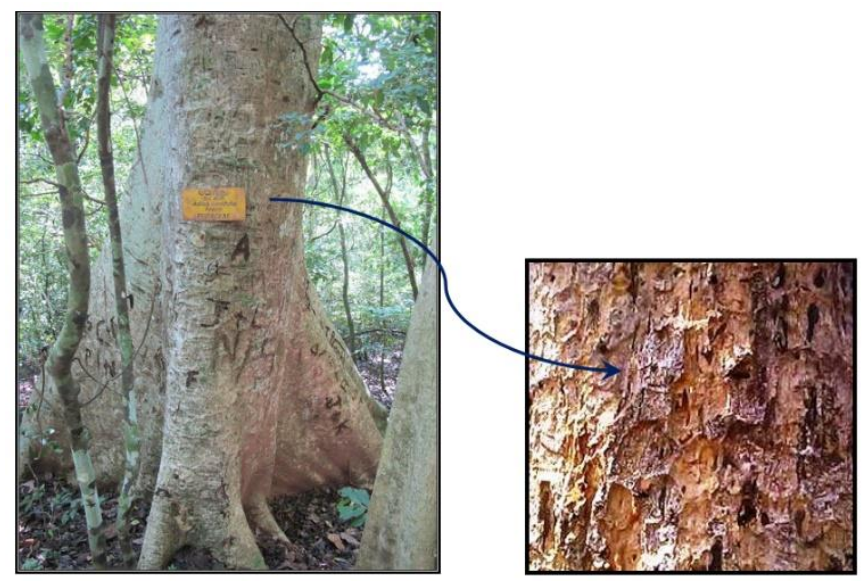

Figure 1. Bark of Adina Cordifolia plant

\section{METHODS AND MATERIAL}

\subsection{Material}

The plant Adina Cordifolia material was collected from sabarkantha district, which belongs to Gujarat, India. Analytical grade gold chloride was purchased from Sigma-Aldrich Chemicals. All glass wear was before used in research work washed with distilled water and dried in an oven. Ultra-pure deionised water used in entire research.

\subsection{Preparation of A. Cordifolia bark extract}

Collected plant bark first washes tap water then again washes with double distilled water and dry it at room temperature for 15-20 days. After dried bark, it was converting into powder form by using the grinder and collects it in neat and clean dry air tight bottle for use of research. Weigh $10 \mathrm{gm}$ of powder takes in $250 \mathrm{ml}$ conical flask and add $100 \mathrm{ml}$ deionised water after that conical flask put on the magnetic stirrer and stir for $30 \mathrm{~min}$ at $60^{\circ} \mathrm{C}$. The extract was cool down at room temp and filtered with Whatman no.1 filter paper and the filtrate obtained was store at room temp at the dark place for further use ${ }^{8}$.

\subsection{Synthesis of Gold Nanoparticles}

The reaction mixture was prepared by $10 \mathrm{ml}$ of $\mathrm{M}$. parvifolia extract was added to $90 \mathrm{ml}$ of an aqueous gold chloride solution in a $250 \mathrm{ml}$ conical flask. The mixture of the solution was kept under vigorous stirring at room temperature for 1 hour. After that, the solution color changed to ruby red from pale yellow indicates the reduction of $\mathrm{Au}^{3+}$ ions to $\mathrm{Au}^{\circ}$. Ruby red colored formation was established after the initial confirmation for the formation of plantmediated gold nanoparticles. 


\subsection{Purification of Gold Nanoparticles}

The reaction mixture was centrifuged at $12,000 \mathrm{rpm}$ for $15 \mathrm{~min}$ and particles were washed twice with deionized water and dried at room temp.

\subsection{Characterization of prepared Gold Nanoparticles}

\subsubsection{UV-Visible Spectrophotometer Analysis}

The green synthesized AuNPs characterization was monitored by Shimadzu 1800 UV-Visible spectrophotometer in the wavelength range of 300$700 \mathrm{~nm} .2 \mathrm{~mm}$ caveat and double distilled water were utilized for blank reading.

\subsubsection{FT-IR spectroscopy analysis}

The Fourier Transform Infrared spectra were identified by an FT-IR spectrophotometer (Perkin Elmer Spectrum) using $\mathrm{KBr}$. The sample powder was mixed with $\mathrm{KBr}$ and prepared pallet scanned at the range of $4000-450 \mathrm{~cm}^{-1}$.

\subsubsection{X-ray diffraction (XRD) analysis}

The X-ray diffraction was used to obtaining the crystalline structure and data in the $2 \theta$ range of $20^{\circ}-$ $80^{\circ}$.

The Debye Scherrer formula,

\section{$\mathrm{D}=\mathrm{k} \lambda / \beta \cos \boldsymbol{\theta}$}

Where,

$\mathrm{D}=$ particle diameter size

$\mathrm{K}=$ constant equals

$\Lambda=$ wavelength of the $\mathrm{X}$-ray source

$\beta=$ the full width at half maximum of the diffraction peak

$\Theta=$ the Bragg angle

\subsubsection{Scanning Electron Microscopy (SEM) analysis}

Scanning electron microscopy is one more commonly used technique for characterization of nanoparticles. The surface morphology of AuNPs was analyzed by scanning electron microscope it was performed by SIGMA model and an operating on the voltage of 20 $\mathrm{kV}$ and for operation need a very small amount of dry powder sample put on a grid and removed excess sample with the help of blotting paper.

\subsubsection{Transmission Electron Microscopy (TEM)} Analysis

TEM analysis characterized the size, shape and morphology of the gold nanoparticles and a prepared sample was dried under vacuum in desiccators before placing it in a specimen holder. A thin sample was irradiated with a sharp high-energy electron beam focused by magnetic lance and electron intensity distribute on the beam after interaction with sample and image was recorded by digital camera and display on a computer screen 9 .

\subsection{Antimicrobial activity}

\subsubsection{Test organism for antibacterial activity}

In this study, two type bacteria were collected from the microbiology department, HNGU. One was gram-positive bacteria and another one was gramnegative, Bacillus subtilis (+ve) and Escherichia coli (ve). The bacterial strains were grown and maintained on nutrient agar at $38^{\circ} \mathrm{C}$ in incubation condition for 5 days and the culture was stored at $4^{\circ} \mathrm{C}$ for further experiment work.

\subsubsection{Media preparation}

In the media preparation, B. subtilis and E. coli bacteria were grown in a nutrient agar medium. 2.8 gm nutrient agar powder was added into $100 \mathrm{ml}$ of distilled water for nutrient agar preparation then the prepared medium was kept in the cotton-plugged 
glass container and sterilized in the autoclave at $120^{\circ} \mathrm{C}$ for $20 \mathrm{~min}$.

\subsubsection{Method for testing Antimicrobial Activity of Synthesised Copper Nanoparticles}

Antimicrobial activity of green synthesised nanoparticles was carried out by agar disc diffusion method $^{10-12}$ against B. subtilis (+ve) and E. coli (-ve) bacteria.

The nutrient agar plates were prepared by $20 \mathrm{ml}$ for each of molten media into sterile Petri-plates. Plates were left standing for 10 minutes to let the culture get absorbed.

Using the micro-pipette, $100 \mu$ of sample of nanoparticles suspension was poured into different concentration $(25 \mu l, 50 \mu l, 75 \mu l)$ into each plate. Then Antibiotic-Ampicillin drug was used as positive control. After adding the samples in the wells, the dishes were kept in a refrigerator for an hour for absorption of the samples into the surrounding medium from the well. The plates were transferred into an incubator set at $37^{\circ} \mathrm{C}$ to allow bacterial growth on the medium. After 24 hrs the plates were taken out of the incubator and observed for the zone of bacterial growth inhibition around the wells. The zone of inhibition was measured in millimeters ${ }^{13}$.

\subsection{Anticancer}

For this experiment, RPMI 1640 medium containing $10 \%$ fetal bovine serum and $2 \mathrm{mM} \mathrm{L}$ glutamine for grown the cell lines and cells were incubated into 96 well microtiter plates in $100 \mu \mathrm{l}$ at plating densities depending on the doubling time of individual cell lines. In the microtiter plates added experimental drugs then incubated at $37^{\circ} \mathrm{C}$ temperature, presence of 5\% carbon dioxide and $95 \%$ air and $100 \%$ relative humidity for 24 hours to the addition of experimental drugs after the procedure of cell incubation.

The experimental drugs were initiating solubilized in $100 \mathrm{mg} / \mathrm{ml}$ dimethyl sulfoxide and diluted in $1 \mathrm{mg} / \mathrm{ml}$ water then stored frozen prior to use. Preparation of diluted complete medium containing test article to $100 \mu \mathrm{g} / \mathrm{ml}, 200 \mu \mathrm{g} / \mathrm{ml}, 400 \mu \mathrm{g} / \mathrm{ml}$ and $800 \mu \mathrm{g} / \mathrm{ml}$ by frozen concentrate $1 \mathrm{mg} / \mathrm{ml}$ for the time of drug addition.

Microtiter wells containing $90 \mu \mathrm{l}$ of medium and added $10 \mu \mathrm{l}$ of different drug dilution. The required final drug concentration was i.e. $10 \mu \mathrm{g} / \mathrm{ml}, 20 \mu \mathrm{g} / \mathrm{ml}$, $40 \mu \mathrm{g} / \mathrm{ml}$ and $80 \mu \mathrm{g} / \mathrm{ml}$. Prepared plates were incubated for two days in standard condition after the compound addition and assay was completed by the addition of cold TCA.

The cell were fixed in situ by the gentle addition of $50 \mu \mathrm{l}$ of cold $30 \%(\mathrm{w} / \mathrm{v})$ TCA and incubated for 1 hour at $4 \mathrm{oC}$. Now, discard the supernent from the plates and the plates were washed 5-6 times with tap water and air dried then added to each of the wells sulforhodamine B solution $(50 \mu \mathrm{l})$ at $0.4 \%(\mathrm{w} / \mathrm{v})$ in $1 \%$ acetic acid and the plates were incubated for 20 minutes at room temperature. When staining was completed unbound dye and the residual dye was removed after staining with $1 \%$ acetic acid by washing five times then plates was air dried. The bond stain was evaluated with $10 \mathrm{mM}$ Trizma base and shown reading of absorbance was on the plate reader at 540-690 $\mathrm{nm}$ reference wavelengths ${ }^{14-15}$.

\section{RESULTS AND DISCUSSION}

\subsection{Color change}

Pale yellow to ruby red color 


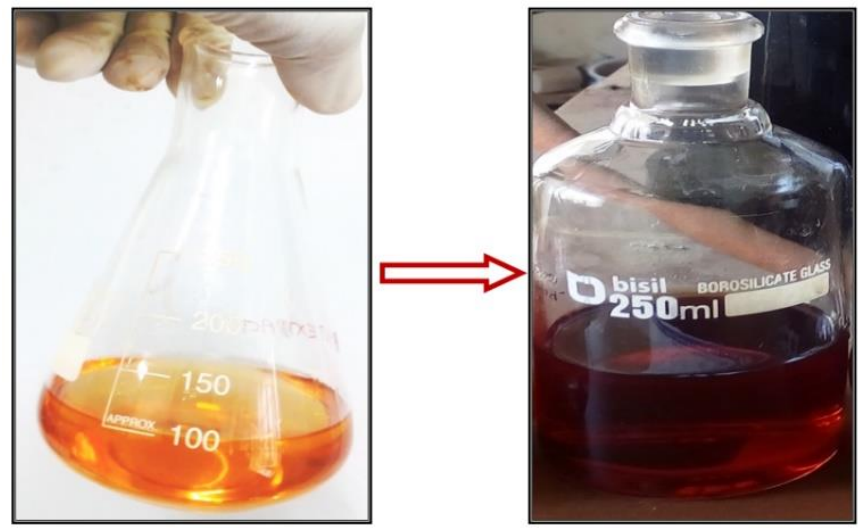

Figure 2. Showing color change of Adina cordifolia plant bark extracts containing before and after synthesis of AuNPs

\subsection{UV-visible Spectroscopy}

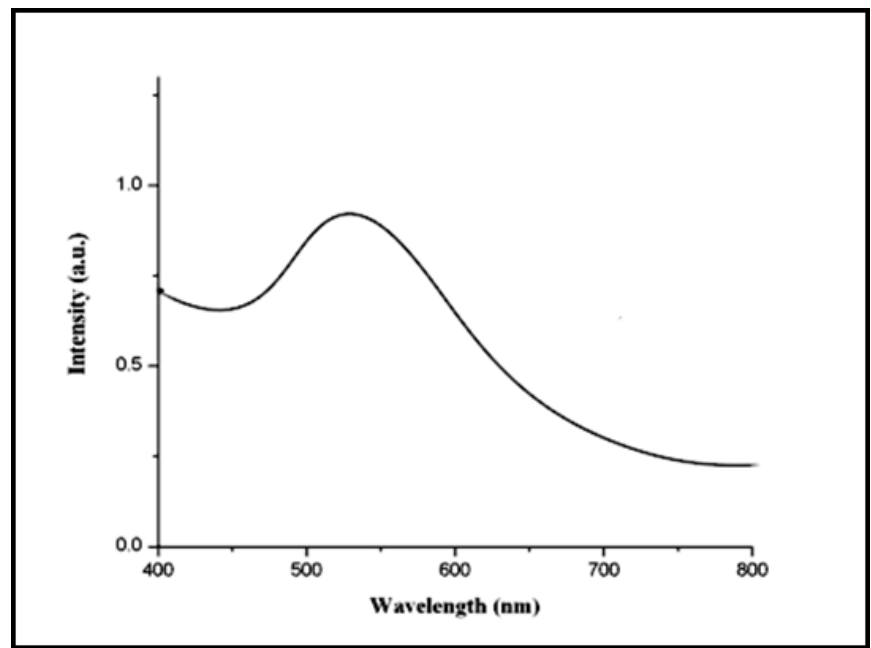

Figure 3. UV-visible spectra of gold nanoparticles

The characterization of gold nanoparticles by UV-Vis spectra from the range of $400-800 \mathrm{~nm}$ the absorption spectra were obtained at $525-530 \mathrm{~nm}$ in graph represent.

\subsection{Fourier Transform Infrared Spectroscopy (FTIR)}

FTIR gives the information about present functional groups in synthesised copper nanoparticles and it shows in (fig. 4) clearly. In the spectra the peak at $3298.28 \mathrm{~cm}^{-1}$ and $3324.21 \mathrm{~cm}^{-1}$ indicating the presence of $-\mathrm{NH}$ or $-\mathrm{OH}$ group stretching in amino acids alcohols and phenols, Stretching at $2926.01 \mathrm{~cm}^{-1}$ corresponds to $\mathrm{C}-\mathrm{H}$ stretching in alkanes and aldehydes, stretching at $1648.12 \mathrm{~cm}-1$ indicate the presence of $>\mathrm{C}=\mathrm{O}$ group and the peak at $1103.28 \mathrm{~cm}^{-1}$ corresponds to $\mathrm{C}-\mathrm{O}$ stretching and the weak peaks in between $850.61 \mathrm{~cm}^{-1}$ to $526.57 \mathrm{~cm}^{-1}$ are associated to halo compounds stretching ${ }^{16-17}$. Hence these observations indicated the formation of AuNPs associated with metabolites protein like terpenoids contain functional groups as alcohols, phenols aldehydes, ketones and carboxylic acids. Kulkarni et al reported the bio-entities could probably play a double role of fabrication and stabilization of gold nanoparticles in the aqueous solution ${ }^{18}$.

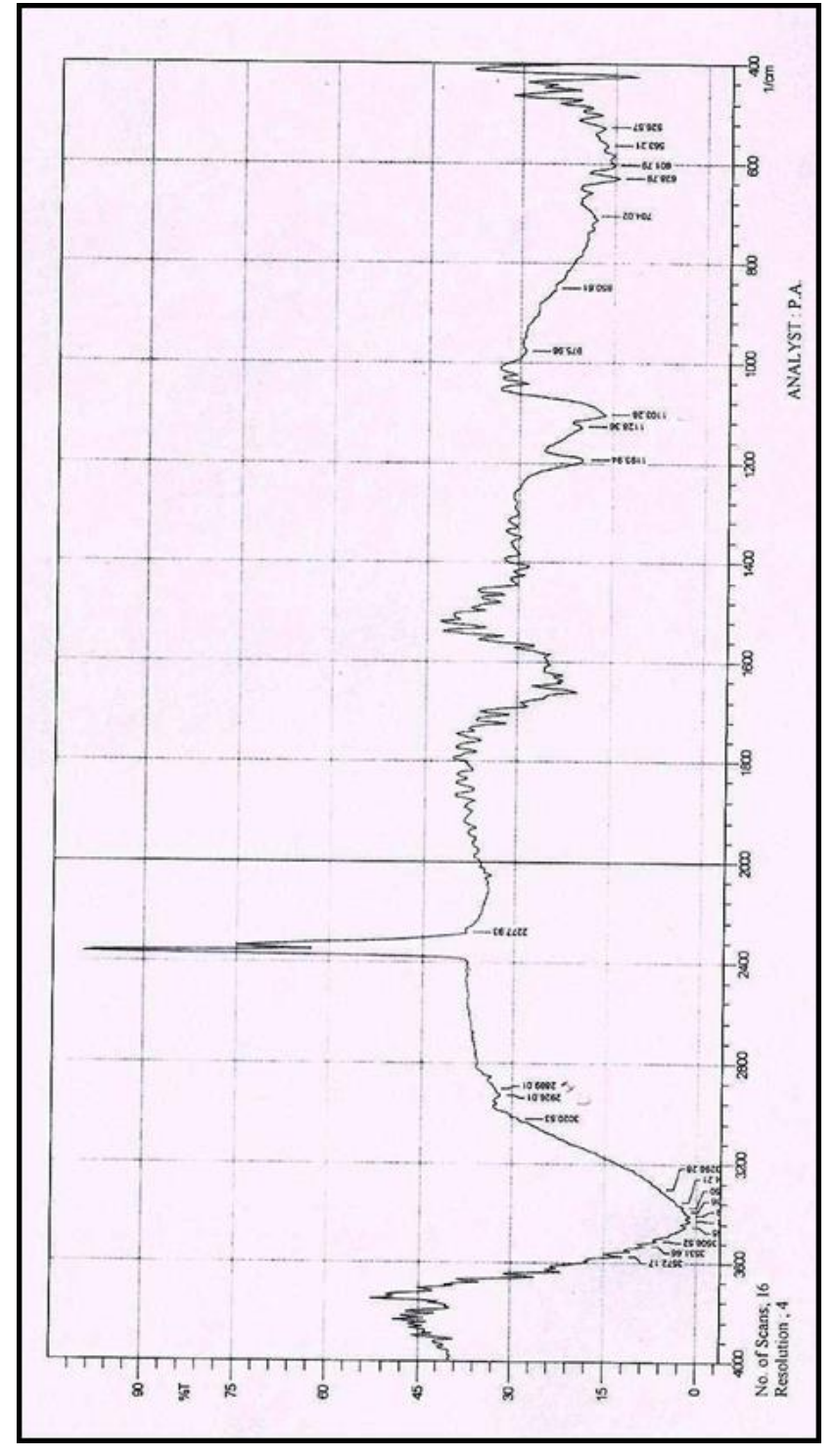

Figure 4. FTIR spectra of copper nanoparticles 


\subsection{X-ray diffraction}

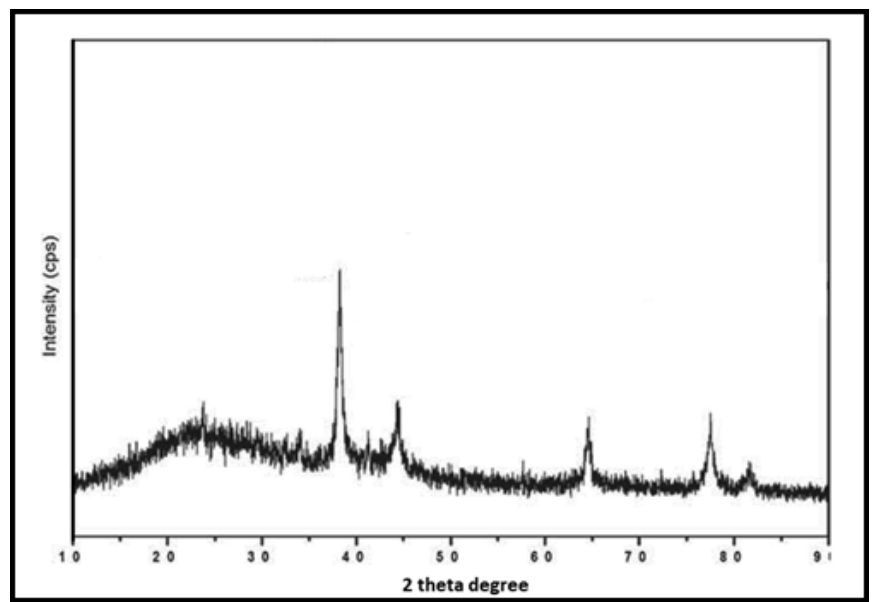

Figure 5. XRD pattern of gold nanoparticles

synthesized from an extract

X-ray diffraction pattern study confirmed the phase of AuNPs and the peaks observed at $2 \theta$ values of $38.3^{\circ}$, $44.6^{\circ}, 64.4^{\circ}, 78.2^{\circ}$ and $81.5^{\circ}$ correspond to crystal planes of (111), (200), (220), (311) and (222) of gold nanoparticles ${ }^{19-20}$. The diffraction peaks denote as crystalline phase, fcc crystal structure in (Fig. 5). The particle average size was calculated by the Scherrer formula and determines $15.3 \mathrm{~nm}$. Citrus reticulate, Citrus sinensis and Chrysopogon zizanioides have a similar pattern reported of XRD for gold nanoparticles ${ }^{21-23}$.

\subsection{Scanning Electron Microscopy (SEM) analysis}

The gold nanoparticles size determined by scanning electron microscope image, in the surface morphology study of AuNPs average size was $14-32$ $\mathrm{nm}$; (fig.6) shows the existence of symmetrical spherical shape ${ }^{24}$.

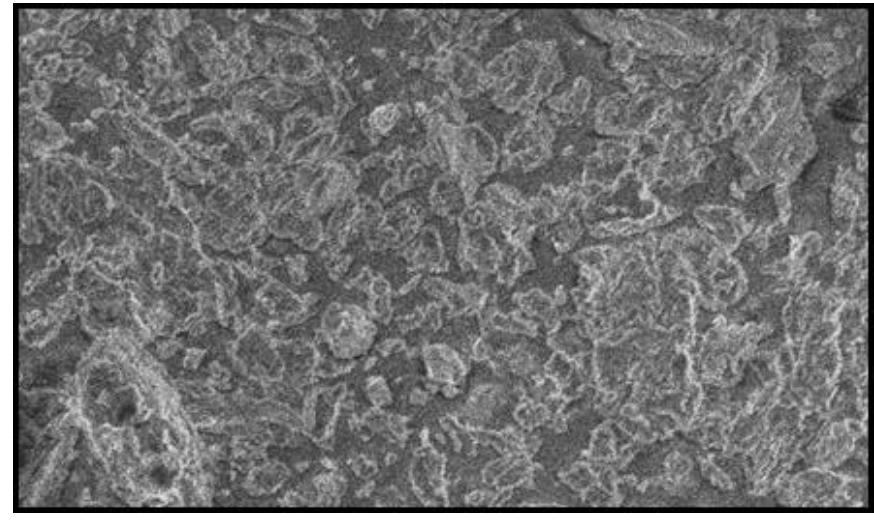

Figure 6. SEM analysis of gold nanoparticles

\subsection{Transmission Electron Microscopy (TEM)} analysis

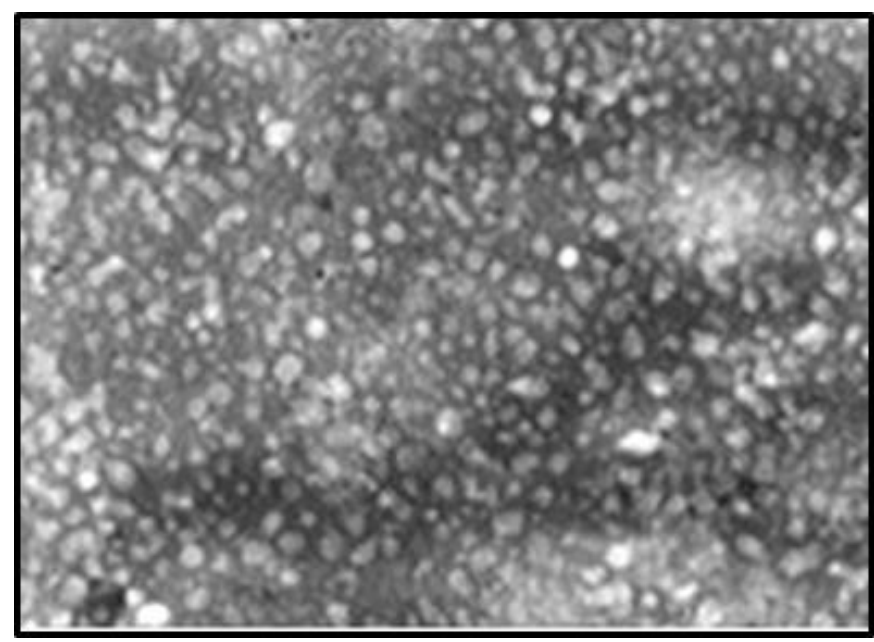

Figure 7. TEM analysis of copper nanoparticles

The image of Silver nanoparticles synthesised using an aqueous extract of (plant name) shown in (fig.7) the synthesised AuNPs was spherical in shape and an average diameter of 8-17 $\mathrm{nm}$. Singh et al. have reported a similar geometry of synthesized silver and gold nanoparticles using natural precursor clove ${ }^{25}$.

\subsection{Antimicrobial activity}

The antimicrobial activity of green synthesised gold nanoparticles against two human pathogenic bacteria such as Bacillus subtilis and Escherichia coli. Here Bacillus subtilis is gram +ve and Escherichia coli is gram -ve bacteria were evaluated and compared to a 
commercial antibiotic drug Ofloxacin. Synthesised AuNPs showed the clear diameter of the zone of inhibition around the well wherein the suspension of AuNPs was applied. The obtained result was presented in table and figure.

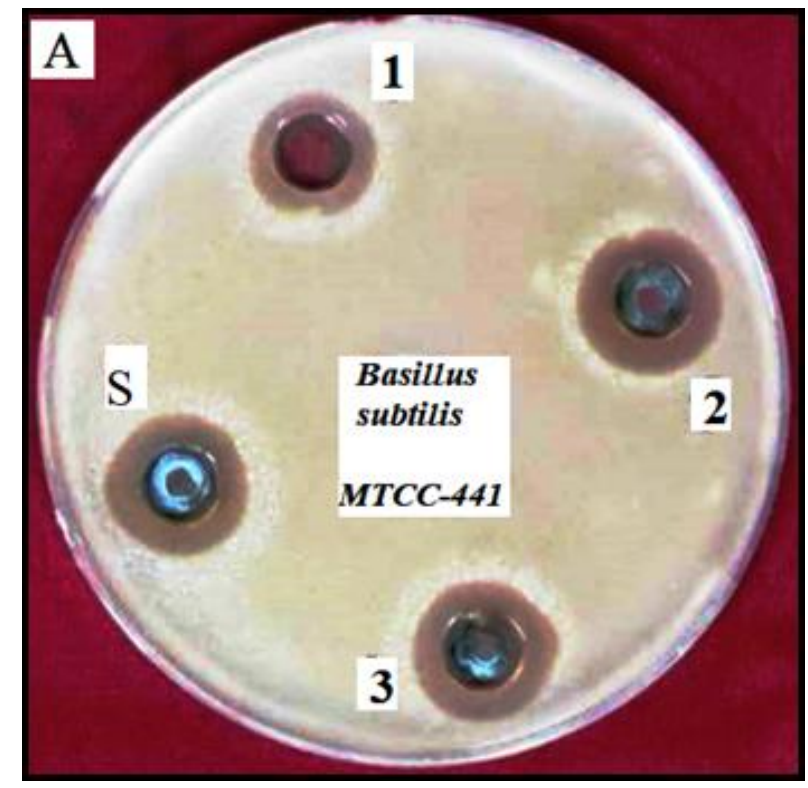

Figure 8. Bacterial growth inhibition against Bacillus

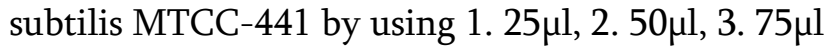
and S. control sample (Ofloxacin)

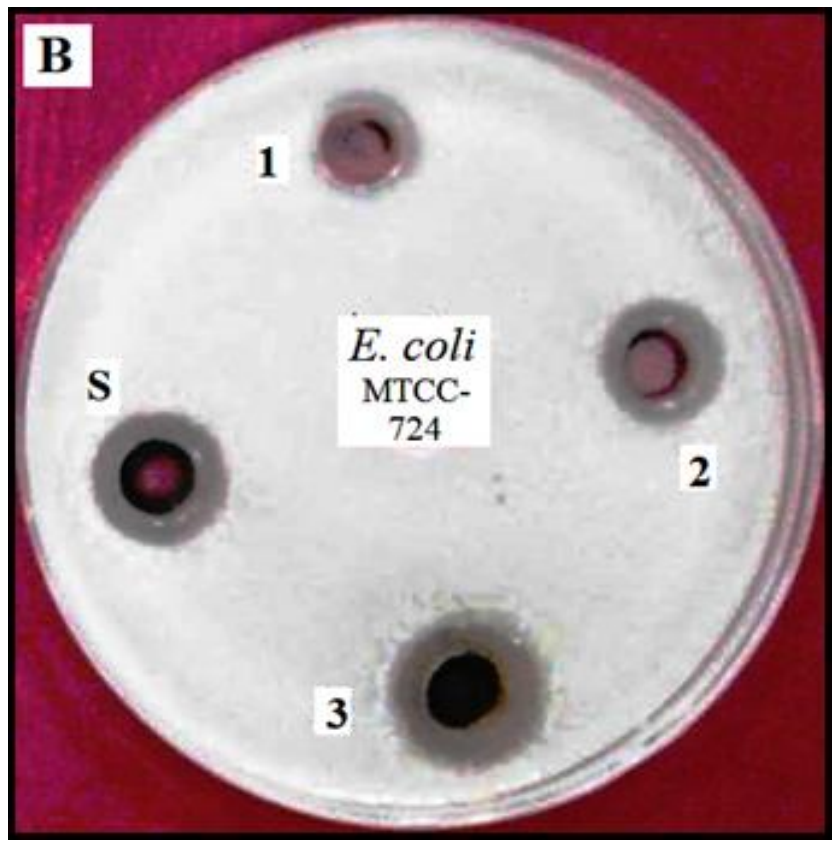

Figure 9. Bacterial growth inhibition against E. coli MTCC-724 by using 25 $\mu \mathrm{l}, 2.50 \mu \mathrm{l}, 3.75 \mu \mathrm{l}$ and S. control sample (Ofloxacin)
Table 1. Zone of diameter area ( $\mathrm{mm})$ exhibited by the formed gold Nanoparticles against pathogenic bacteria

\begin{tabular}{|c|c|c|}
\hline \multirow{2}{*}{$\begin{array}{c}\text { Concentration } \\
(\mu \mathrm{l})\end{array}$} & $\begin{array}{c}\text { Diameter of zone of inhibition } \\
(\mathrm{mm})\end{array}$ \\
\cline { 2 - 3 } & $\begin{array}{c}\text { Bacillus } \\
\text { subtilis } \\
\text { MTCC-441 }\end{array}$ & $\begin{array}{c}\text { Escherichia } \\
\text { Coli } \\
\text { MTCC-724 }\end{array}$ \\
\hline $25 \mu \mathrm{l}$ & 7.3 & 6.5 \\
\hline $50 \mu \mathrm{l}$ & 9.5 & 8.0 \\
\hline $75 \mu \mathrm{l}$ & 10.7 & 10.2 \\
\hline Standard Drug & 13.5 & 12.6 \\
\hline Ofloxacin & & \\
\hline
\end{tabular}

\subsection{Anticancer activity}

Table 2. \% control growth of Human Cancer Cell line MCF-7

\begin{tabular}{|c|c|c|c|c|}
\hline \multicolumn{5}{|c|}{ Human Breast Cancer Cell Line MCF-7 } \\
\hline & \multicolumn{4}{c|}{ \% Control Growth } \\
\hline & \multicolumn{4}{|c|}{ Drug Concentrations $(\mu \mathrm{g} / \mathrm{ml})$} \\
\hline Experiment & 10 & 20 & 30 & 40 \\
& $\mu \mathrm{g} / \mathrm{ml}$ & $\mu \mathrm{g} / \mathrm{ml}$ & $\mu \mathrm{g} / \mathrm{ml}$ & $\mu \mathrm{g} / \mathrm{ml}$ \\
\hline Sample & -64.8 & -59.1 & -56.6 & -43.1 \\
\hline ADR & -71.0 & -69.1 & -80.5 & -69.8 \\
\hline
\end{tabular}

Per cent growth was calculated on a plate-by-plate basis for test wells relative to control wells. Per cent Growth was expressed as the ratio of average absorbance of the test well to the average absorbance of the control wells $* 100$. 
Using the six absorbance measurements [time zero $(\mathrm{Tz})$, control growth $(\mathrm{C})$, and test growth in the presence of drug at the four concentration levels (Ti)], the percentage growth was calculated at each of the drug concentration levels. Percentage growth inhibition was calculated as: $[\mathrm{Ti} / \mathrm{C}] \mathrm{x} 100 \%$

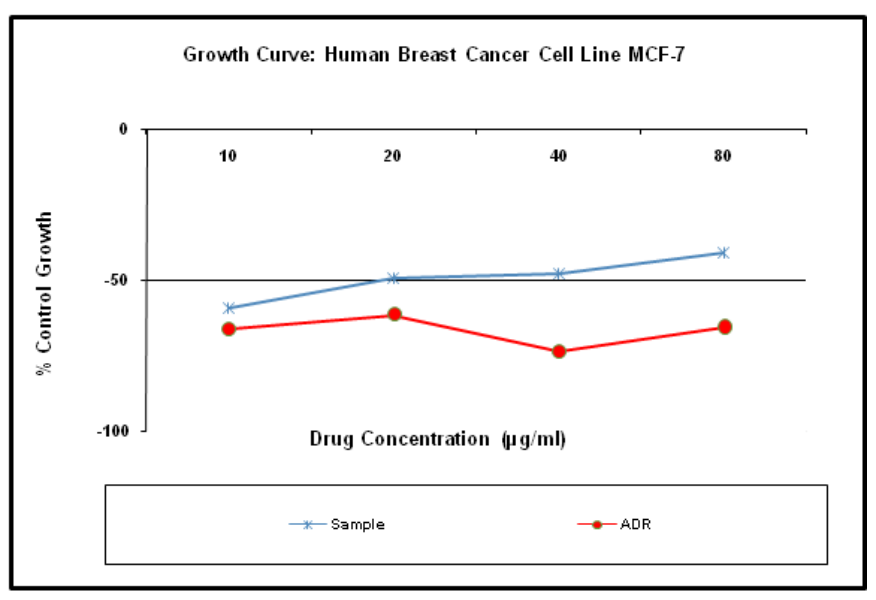

Figure 10. Growth curve: Human Breast Cancer cell line MCF-7

Table 3. Drug concentrations $(\mu \mathrm{g} / \mathrm{ml})$ calculated from graph

\begin{tabular}{|c|c|}
\hline \multirow{2}{*}{ MCF-7 } & $\begin{array}{c}\text { Drug concentrations } \\
(\mu \mathrm{g} / \mathrm{ml}) \text { calculated } \\
\text { from graph }\end{array}$ \\
\cline { 2 - 2 } & GI50* \\
\hline Sample & $<10$ \\
\hline ADR & $<10$ \\
\hline
\end{tabular}

Where,

GI50 $=$ Concentration of drug causing 50\% inhibition of cell growth

ADR = Adriamycin, Positive Control Compound GI50 value of $\leq 10^{\wedge}-6$ molar (i.e. $1 \mu$ molar) or $\leq$ $10 \mu \mathrm{g} / \mathrm{ml}$ is considered to demonstrate activity in case of pure compounds. For extracts, GI50 value $\leq 20$ $\mu \mathrm{g} / \mathrm{ml}$ is considered to demonstrate activity

\section{IV.CONCLUSION}

In this study, green synthesis of gold nanoparticles were success fully synthesised by using Adina cordifolia plant bark aqueous extract which provides eco-friendly process, less time consuming, an environmentally benign, easy and proficient way for the synthesis of gold nanoparticles. The green synthesised gold nanoparticles were characterized by UV-Visible spectroscopy, FT-IR, XRD, SEM, TEM and their antimicrobial activity was investigated. From UV-Visible spectrophotometer result was confirmed the formation of gold nanoparticles by color changed to ruby red color from pale yellow color indicates the reduction of $\mathrm{Au}^{3+}$ ions to $\mathrm{Au}^{\circ}$. FTIR analysis was confirmed the bending vibrations and stretching bonds present in the sample. The particle size of the metal nanoparticles is $15.3 \mathrm{~nm}$, which was confirmed by XRD and SEM analysis. Spherical in shape and size in the range 8-17 $\mathrm{nm}$ of gold nanoparticle was confirmed by TEM analysis. The antibacterial activity for the synthesised gold nanoparticles was confirmed by the antibacterial activity experiment against Bacillus subtilis and Escherichia coli. Here Bacillus subtilis is gram positive and Escherichia coli is gram negative bacteria were evaluated and compare to a commercial antibiotic drug Ofloxacin by agar well method and the maximum zone of inhibition was higher in gram positive bacteria compared to gram negative bacteria. The synthesised AuNPs showed anticancer activity against MCF-7 breast cancer cell line. The green synthesised gold nanoparticles proved to be potential candidates for medical application antimicrobial and anticancer activity is highly essential.

\section{REFERENCES}

[1]. Maensiri, S., P. Laokul, J. Klinkaewnarong, S. Phokha, V. Promarak, and S. Seraphin. "Indium 
oxide (In2O3) nanoparticles using Aloe vera plant extract: Synthesis and optical properties." J Optoelectron Adv Mater 10 (2008): 161-5.

[2]. Song, Jae-Yong, and Beom-Soo Kim. "Biological synthesis of $\mathrm{Au}$ Core-Ag shell bimetallic nanoparticles using Magnolia kobus leaf extract." Korean Chemical Engineering Research48, no. 1 (2010): 98-102.

[3]. Kim, Yong Soon, Jin Sik Kim, Hyun Sun Cho, Dae Sik Rha, Jae Min Kim, Jung Duck Park, Byung Sun Choi et al. "Twenty-eight-day oral toxicity, genotoxicity, and gender-related tissue distribution of silver nanoparticles in SpragueDawley rats." Inhalation toxicology 20, no. 6 (2008): 575-583.

[4]. Parida, Umesh Kumar, Birendra Kumar Bindhani, and Padmalochan Nayak. "Green synthesis and characterization of gold nanoparticles using onion (Allium cepa) extract." World Journal of Nano Science and Engineering 1, no. 04 (2011): 93.

[5]. Tomar, Rajesh Singh, and Vikas Shrivastava. "Synthesis of Gold Nanoparticles: A Biological Approach." Synthesis 3, no. 2 (2014): 5.

[6]. https://en.wikipedia.org/wiki/Haldina

[7]. https://www.researchgate.net/287179487 A comprehensive review on Adina cordifolia

[8]. Arunachalam, Kantha D., Sathesh Kumar Annamalai, and Shanmugasundaram Hari. "One-step green synthesis and characterization of leaf extract-mediated biocompatible silver and gold nanoparticles from Memecylon umbellatum." International journal of nanomedicine 8 (2013): 1307.

[9]. Joseph, Akansha Treeza, P. Prakash, and S. S. Narvi. "Phytofabrication and Characterization of Copper Nanoparticles Using Allium Sativum and its Antibacterial Activity." IJSET 4 (2016): 463-473.
[10]. Verma, Raginee. "Antidermmatophytic activitiy in leaf extract of Calotropis Procera (AIT.) and it's structural characterization." (2012).

[11]. Ahmad, Naheed, Seema Sharma, V. N. Singh, S. F. Shamsi, Anjum Fatma, and B. R. Mehta. "Biosynthesis of silver nanoparticles from Desmodium triflorum: a novel approach towards weed utilization." Biotechnology Research International 2011 (2011).

[12]. Li, Zhi, Daeyeon Lee, Xiaoxia Sheng, Robert E. Cohen, and Michael F. Rubner. "Two-level antibacterial coating with both release-killing and contact-killing capabilities." Langmuir 22, no. 24 (2006): 9820-9823.

[13]. Donda, Manisha R., Karunakar Rao Kudle, Jahnavi Alwala, Anila Miryala, B. Sreedhar, and MP Pratap Rudra. "Synthesis of silver nanoparticles using extracts of Securinega leucopyrus and evaluation of its antibacterial activity." Int J Curr Sci 7 (2013): 1-8.

[14]. Vichai, Vanicha, and Kanyawim Kirtikara. "Sulforhodamine B colorimetric assay for cytotoxicity screening." Nature protocols1, no. 3 (2006): 1112.

[15]. Skehan, Philip, Ritsa Storeng, Dominic Scudiero, Anne Monks, James McMahon, David Vistica, Jonathan T. Warren, Heidi Bokesch, Susan Kenney, and Michael R. Boyd. "New colorimetric cytotoxicity assay for anticancerdrug screening." JNCI: Journal of the National Cancer Institute 82, no. 13 (1990): 1107-1112.

[16]. S.D. Ashtaputrey, P.D. Asthaputry and Neha Telane, green synthesis and characterisation of copper nanoparticles derived from Murraya Koenigii leaves extract, Journal of Chemical and Pharmaceutical Sciences, 2017, 10(3), 12881291.

[17]. Sirisha, N. Gandhi1 D., and Smita Asthana. "Microwave Mediated Green Synthesis Of Copper Nanoparticles Using Aqueous Extract 
Of Piper Nigrum Seeds And Particles Characterisation."

[18]. Kulkarni, V., and P. Kulkarni. "Synthesis of copper nanoparticles with aegle marmelos leaf extract." Nanosci Nanotechnol 8 (2014): 401404.

[19]. Jayaseelan, Chidambaram, Rajendiran Ramkumar, Abdul Abdul Rahuman, and Pachiappan Perumal. "Green synthesis of gold nanoparticles using seed aqueous extract of Abelmoschus esculentus and its antifungal activity." Industrial Crops and Products 45 (2013): 423-429.

[20]. Karthik, L., Gaurav Kumar, Tarun Keswani, Arindam Bhattacharyya, B. Palakshi Reddy, and KV Bhaskara Rao. "Marine actinobacterial mediated gold nanoparticles synthesis and their antimalarial activity." Nanomedicine: Nanotechnology, Biology and Medicine 9, no. 7 (2013): 951-960.

[21]. Jayaseelan, Chidambaram, Rajendiran Ramkumar, Abdul Abdul Rahuman, and Pachiappan Perumal. "Green synthesis of gold nanoparticles using seed aqueous extract of Abelmoschus esculentus and its antifungal activity." Industrial Crops and Products 45 (2013): 423-429.

[22]. Sujitha, Mohanan V., and Soundarapandian Kannan. "Green synthesis of gold nanoparticles using Citrus fruits (Citrus limon, Citrus reticulata and Citrus sinensis) aqueous extract and its characterization." Spectrochimica Acta Part A: Molecular and Biomolecular Spectroscopy 102 (2013): 15-23.

[23]. Arunachalam, Kantha D., and Sathesh Kumar Annamalai. "Chrysopogon zizanioides aqueous extract mediated synthesis, characterization of crystalline silver and gold nanoparticles for biomedical applications." International journal of nanomedicine 8 (2013): 2375.
[24]. Noruzi, Masumeh, Davood Zare, Kamyar Khoshnevisan, and Daryoush Davoodi. "Rapid green synthesis of gold nanoparticles using Rosa hybrida petal extract at room temperature." Spectrochimica Acta Part A: Molecular and Biomolecular Spectroscopy 79, no. 5 (2011): 1461-1465.

[25]. Singh, Ashwani Kumar, Mahe Talat, D. P. Singh, and O. N. Srivastava. "Biosynthesis of gold and silver nanoparticles by natural precursor clove and their functionalization with amine group." Journal of Nanoparticle Research 12, no. 5 (2010): 1667-1675.

[26]. Hutchings, Graham J., Mathias Brust, and Hubert Schmidbaur. "Gold—an introductory perspective." Chemical Society Reviews 37, no. 9 (2008): 1759-1765.

Cite this article as :

Shaileshkumar C Kotval, "Green Synthesis of Gold Nanoparticles using Adina Cordifolia Bark Extract and its Antimicrobial and in Vitro Anticancer Study", International Journal of Scientific Research in Science and Technology (IJSRST), Online ISSN : 2395-602X, Print ISSN : 2395-6011, Volume 6 Issue 4, pp. 143-152, July-August 2019. Available at doi : https://doi.org/10.32628/IJSRST196426 Journal URL : http://ijsrst.com/IJSRST196426 